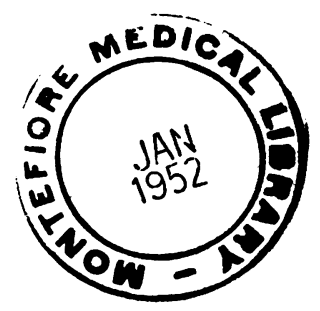

\title{
RETROGRADE AXONAL CHANGES OF THE DE-AFFERENTATED NUCLEUS GRACILIS FOLLOWING MID-BRAIN TRACTOTOMY
}

\author{
BY \\ P. GLEES, J. SOLER, and R. A. BAILEY \\ From the University Laboratory of Physiology, Oxford
}

While retrograde cell changes in the central nervous system are well known, degeneration of that portion of the axon which lies central to a lesion is very seldom observed. For this reason the relevant histological observation of two human cases is recorded here.

In both cases the operation of mid-brain tractotomy had been performed by one of us (R.A.B.) on the right side, involving the medial fillet on this side. It was of great histological interest to find that Marchi degeneration had not only occurred in the medial fillet above the lesion, but that there was also retrograde degeneration towards the left nucleus gracilis. This type of Marchi degeneration, referred to in the literature as " retrograde", is of considerable practical and theoretical interest. Opinion about its occurrence differs widely, as Combs (1951) has recently pointed out. The following two cases seem to throw light on the occurrence of this phenomenon.

\section{Material}

A description of the degenerative changes in certain fibre tracts in the material of R.W. and M.W. has already been made (for the central tegmental tract see Glees and Zander, 1950 ; for the spinothalamic tract see Glees and Bailey, 1951).

Case 1.-R. W. was suffering from a malignant metastasis of the second lumbar vertebra, which led to painful paraplegia. To relieve the pain, a mid-brain tractotomy on the right side was performed on August 17, 1949, and a lateral chordotomy on the left side at the level of the fourth thoracic segment on August 24, 1949. The patient died on October 4, 40 days after the last operation and 49 days after tractotomy.

Case 2.-M. W., aged 28, became ill in 1948 with pain in both legs and backache. Exploratory laminectomy was carried out in July, 1949, and adhesions of the spinal cord and of the cauda equina, caused by a malignant disease, were found. Right mid-brain tractotomy was performed on October 26, 1949. Death occurred on June 27, 1950, eight months after this operation.

\section{Methods}

The brain and spinal cord in both cases were subdivided into various small blocks, some of which were used for Marchi impregnation (Swank and Davenport, 1935), while others were stained with the Weigert method. The Nissl method (cresyl violet) and a silver impregnation (Glees, 1946) were also used.

\section{Histological Findings}

In R.W. a malignant growth involving the second lumbar vertebra had caused compression of the cauda equina, while in M.W. the infiltration of the roots and meninges of the cauda equina by a tumour had compressed the spinal cord itself. Marchi degeneration had occurred in the posterior columns, as well as degeneration of other tracts (Fig. 1). In both cases a mid-brain tractotomy had been carried out on the right side (Fig. 2), causing a subsequent ascending degeneration of the medial fillet; we were however surprised to find that Marchi degeneration extended also into the pons and medulla towards the left nucleus of Goll (Fig. 3). The degeneration just below the level of the mid-brain lesion was at first scanty, but increased at medullary level and was very conspicuous close to the nucleus gracilis, while no such degeneration could be traced towards the nucleus cuneatus.

With regard to its topographical position, the retrograde degeneration was found to occupy in each case a ventral and lateral position in the interolivary space and, at pontine level, a more lateral and somewhat ventral position in relation to the undegenerated fibres of the medial fillet (Fig. 4).

Striking changes can also be seen in the Nissl picture (Fig. 5). When one compares the nuclei graciles of both sides and the nucleus gracilis on the left with the left nucleus cuneatus, one sees that the medial side of the left nucleus gracilis is for the greater part denuded of cells and that those cells which are present show various chromatolytic changes and are shrunken, with dark, diffusely 

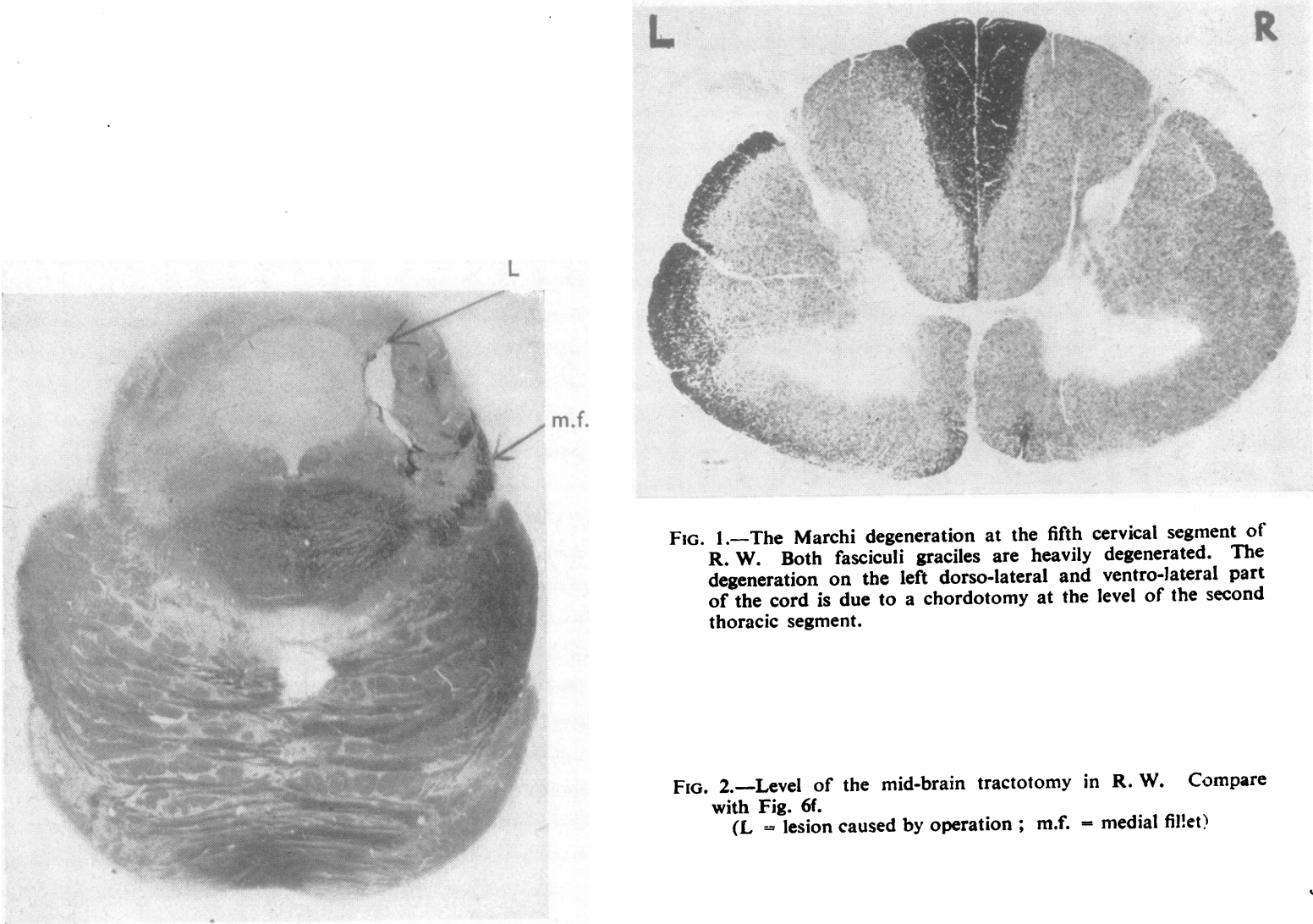

Fig. 1.-The Marchi degeneration at the fifth cervical segment of R. W. Both fasciculi graciles are heavily degenerated. The degeneration on the left dorso-lateral and ventro-lateral part of the cord is due to a chordotomy at the level of the second thoracic segment.

Fig. 2.-Level of the mid-brain tractotomy in R. W. Compare with Fig. $6 f$.

$(\mathrm{L}=$ lesion caused by operation ; m.f. $=$ medial fillet $)$

Fig. 3.-The retrograde Marchi degeneration in the case $R$. W. Both graciles nuclei show an equal amount of Marchi degeneration, but retrograde axonal changes are seen only on the left side and are marked with an arrow.

(c.c. = central canal)

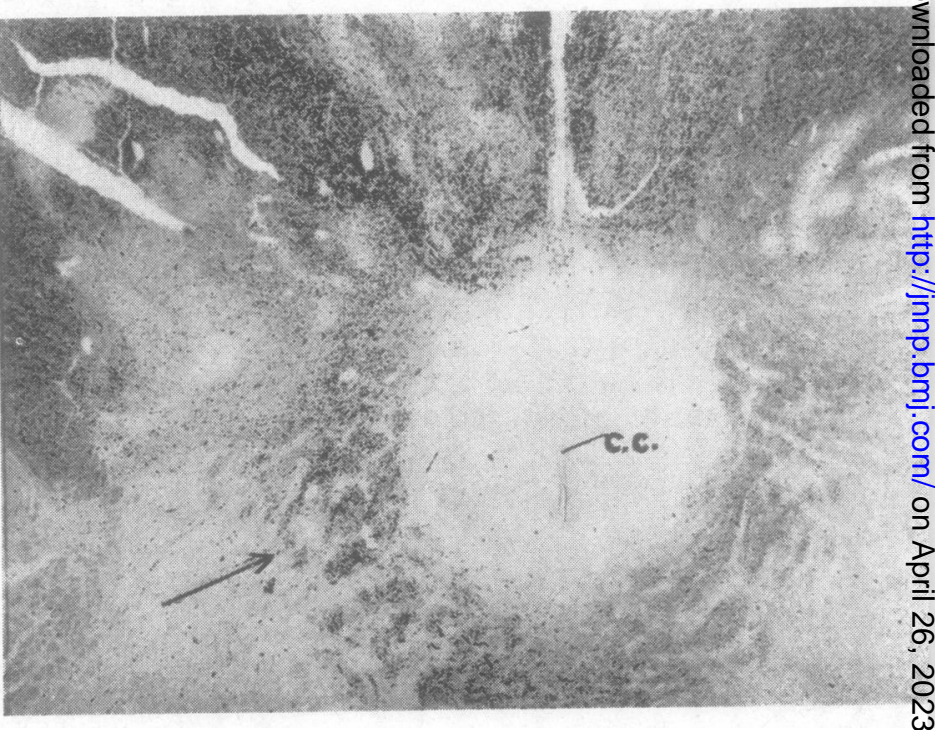




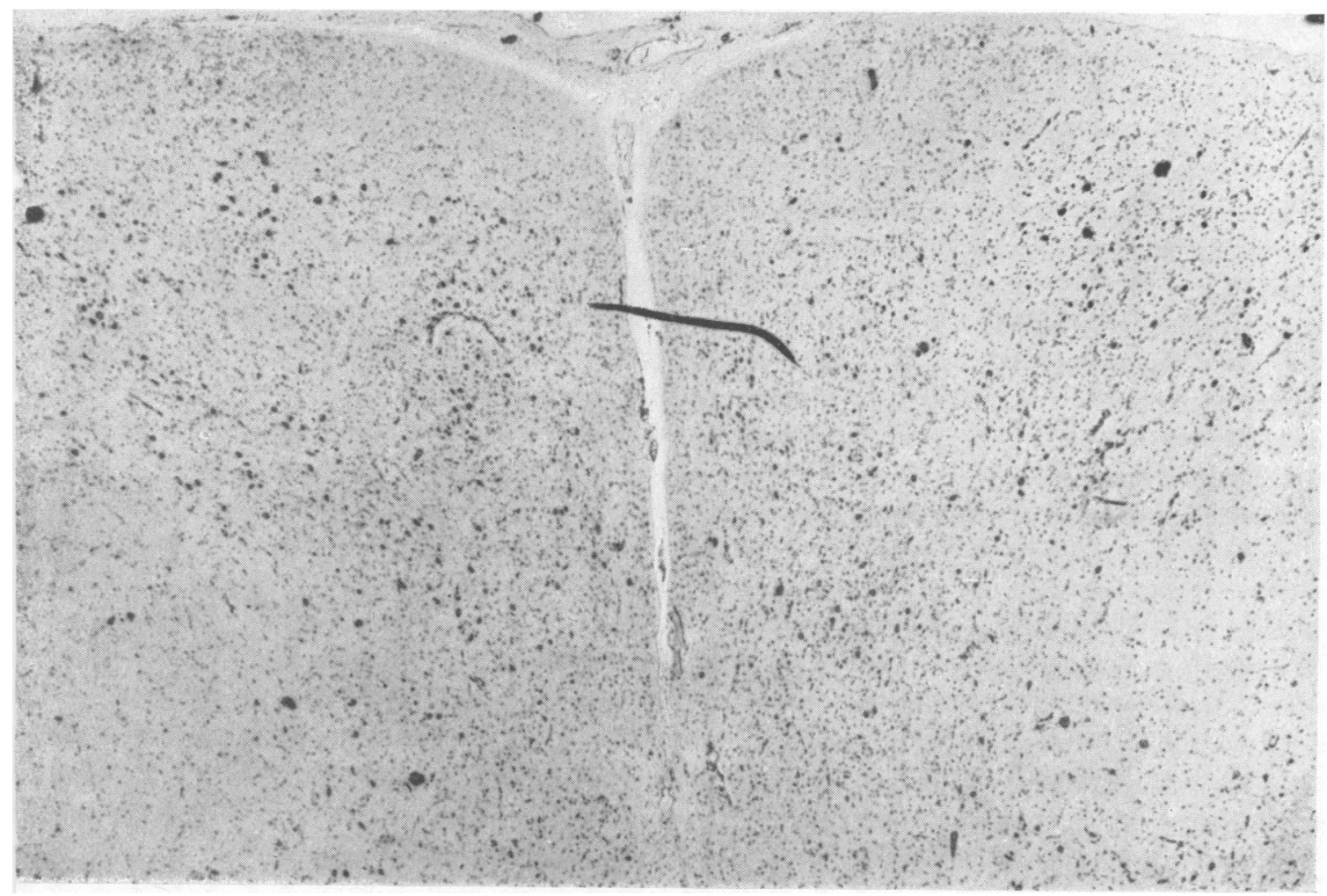

"IG. 5.-A Nissl picture of the lower portion of the medulla of M. W. under low power. The left nucleus gracilis is on the right side of the picture. Many of its cells are gone and those present show marked degeneration under higher power.

IG. 4.-Medulla, Marchi of Case 2 (M. W.). Arrow 1 marks the position of the retrograde degeneration originating from the left nucleus gracilis, and arrow 2 the degenerated tegmentoolivary tract following mid-brain tractotomy.

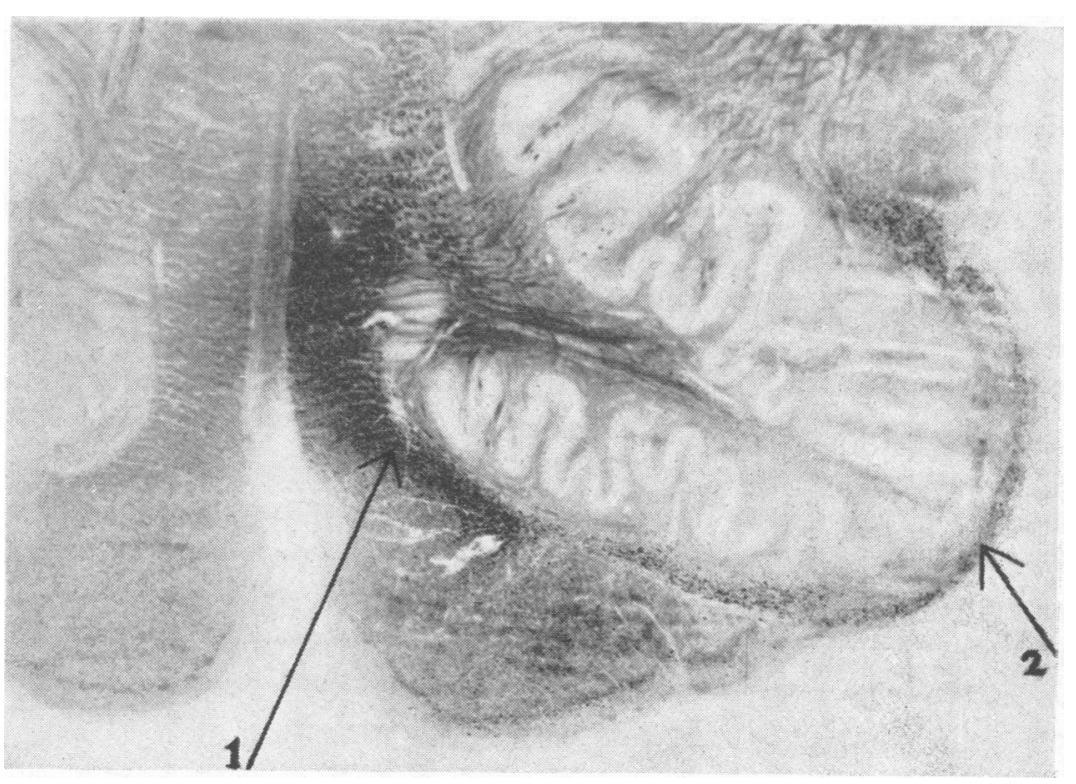




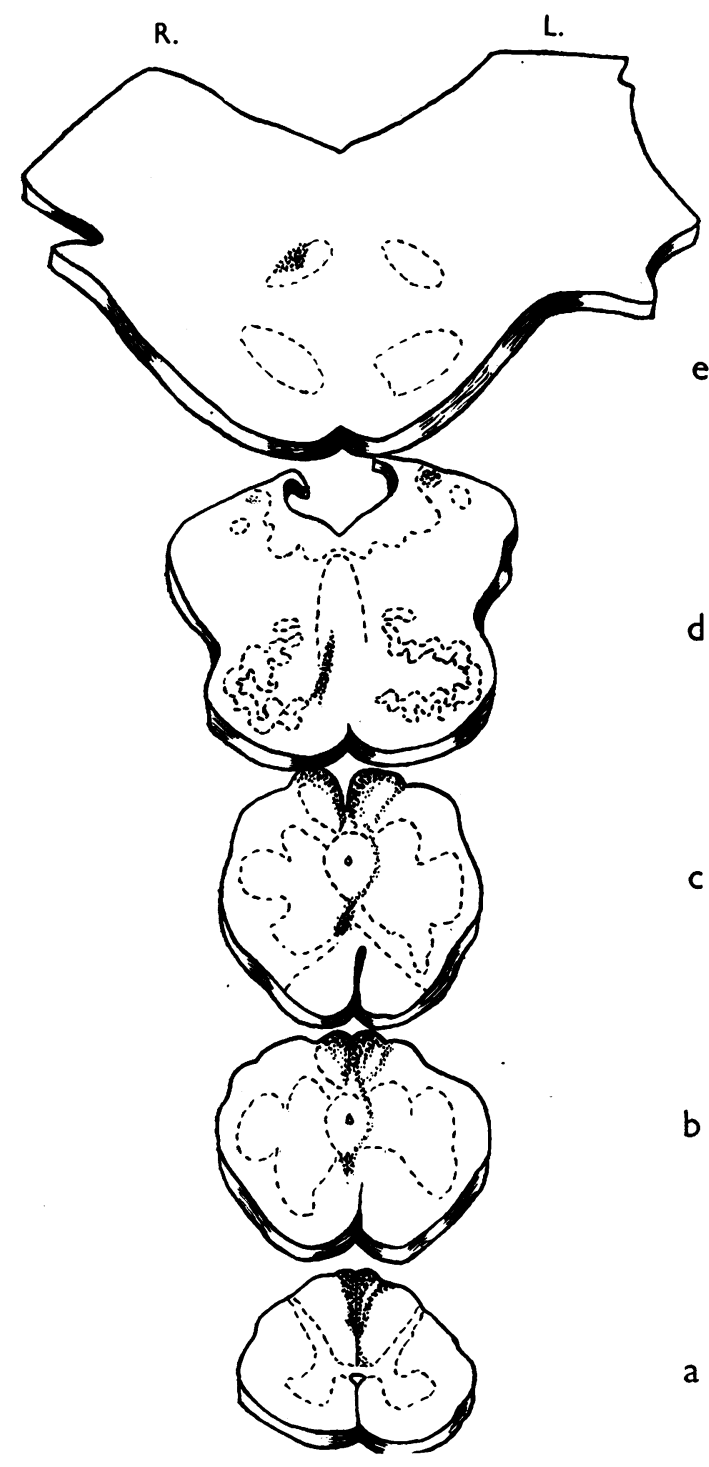

R.

C

Fig. 6.-Diagram drawn from slides, using the microprojector, of Case 1 (as seen from above).

$a$ = degeneration in the posterior columns; $b=$ their terminations in the nucleus gracilis ; b, c, d, e - retrograde degeneration; $f=$ the tractotomy lesion at mid-brain level ; $g=$ the degeneration in the medial fillet resulting from the tractotomy lesion.

FIG. 7.-The retrograde degeneration of a portion of the right medial fillet in Case 2 (M. W.) at lower pontine level. Compare with Fig. 6e. Note that the amount of retrograde degeneration is less than at medullary level.

(tr. t.o. = tractus tegmento-olivaris ; m.f. = medial fillet)

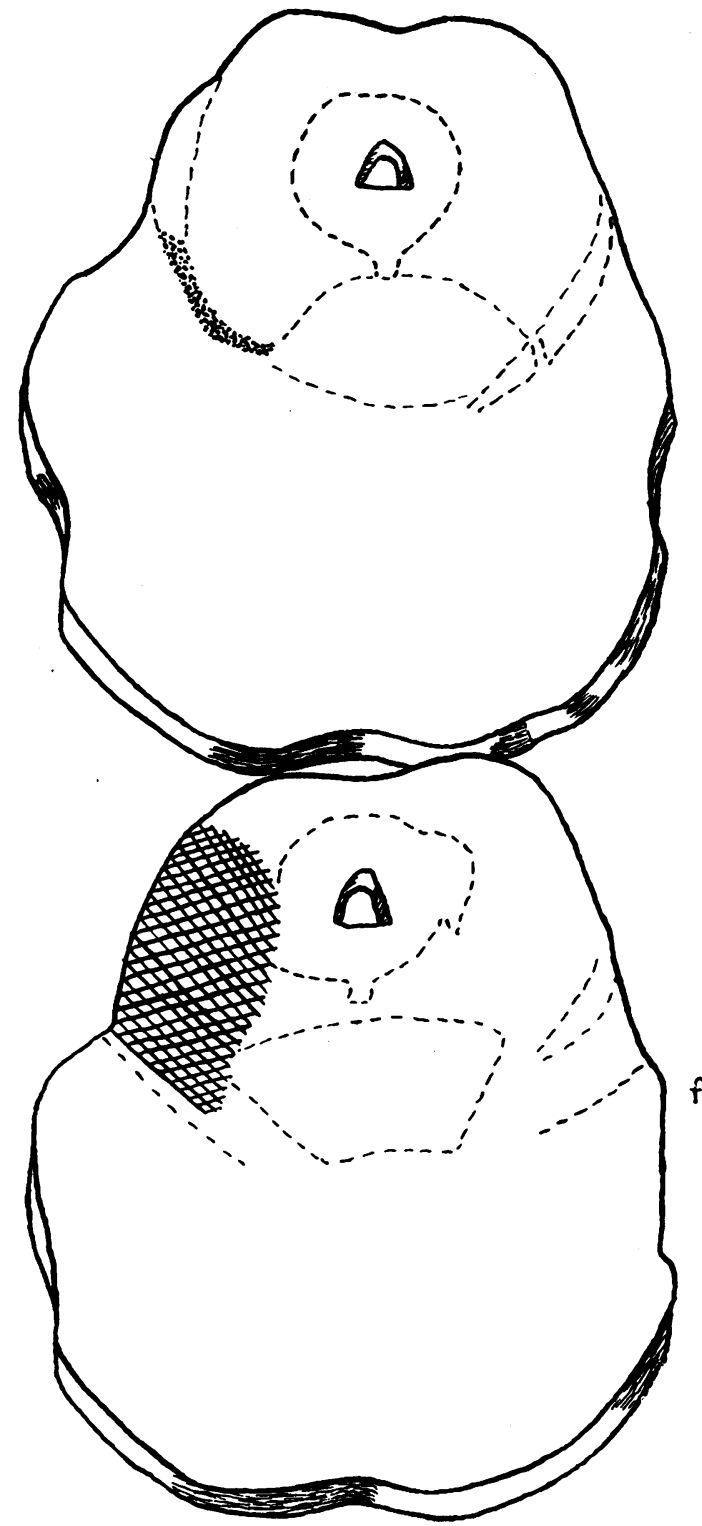


staining cytoplasm and small nuclei. The cell changes in the left nucleus gracilis are more severe than in the left nucleus cuneatus, where chromatolytic changes can also be seen. In the silver picture, swollen axons-some of them fragmentedcan be seen emerging from the left nucleus gracilis. The silver picture corresponds to that of the Marchi preparations in that it shows the retrograde axonal changes, although the Marchi picture is more obvious.

\section{Discussion}

The fact that retrograde degeneration occurred after de-afferentation and partial cutting of the axon is of great theoretical interest. In some ways the present cases illustrating this retrograde Marchi degeneration assume the condition of an ideal experiment. Axonal amputation by cutting the right medial fillet at mid-brain level has affected the neurons of both nucleus gracilis and nucleus cuneatus on the left side. Chromatolytic changes in response to axonal severance can be seen in both nuclei. However, retrograde Marchi degeneration of the remaining portion of the axon originating from cells of the cuneate nucleus did not occur, while it could be clearly observed in fibres whose parent cells had both de-afferentation, due to degeneration of the fasciculus gracilis, and a cutting of the axon at mid-brain level. Furthermore, the right fasciculus gracilis was also degenerated to the same extent as the left, but as no axonal damage had involved cells of the right nucleus gracilis no degeneration (of a retrograde type) of the myelin sheath could be detected.

We would like to stress that the ascending Marchi degeneration of the fasciculi graciles was of the same density on both sides in each case and produced an equal amount of de-afferentation, as we assume that the posterior column nuclei have their afferents in posterior column fibres only (Glees, Livingston, and Soler, 1951 ; Glees and Soler, 1951).

Observations on the lateral geniculate body by Le Gros Clark (1932), Minkowski (1913) and others have shown that transneuronal cell changes follow de-afferentation. This has recently been clearly stated by Penman and Smith (1950) in their work on the trigeminal nuclei. The right nucleus gracilis also shows changes which must be attributed to transneuronal degeneration; but in spite of these cell changes retrograde Marchi degeneration does not appear.

The conclusions are therefore obvious. To obtain retrograde Marchi degeneration axonal cutting is apparently not enough, but only if the main afferent impulses to the parent cells are also cut does this degeneration occur.
The problem of retrograde changes in the central portion of the fibre have been discussed by Spatz $(1920,1921)$, who found that after cutting ventral roots the retrograde changes were not limited to the anterior horn cells, but also became apparent in the fragment of the axon central to the cut. Spielmeyer (1922) supports the observations made by Spatz. Brodal (1939), when studying the retrograde cell changes in the inferior olive after cerebellar lesions, saw no retrograde axonal signs and says that there is no unanimous view concerning the retrograde changes in that part of the axon still connected with the cell. Brodal quotes Raimann (1900) and Pilcz (1899), who believe that the changes are only very slow, and he too quotes the findings of Spatz.

Taking our material into account we would like to suggest that cutting the axon combined with de-afferentation may prove to be an excellent means of finding out whether one nucleus is served by one incoming source only, as seems to be the case with the nucleus gracilis. This has been pointed out in a paper to appear shortly (Glees and Soler, 1951), in which the synapses of the nucleus gracilis are investigated. We found that the terminating fibres in this nucleus originated from the fasciculus gracilis only.

Much of the experimental work done by one of us (P.G.) has been carried out with the Marchi technique. In none of that material could retrograde Marchi degeneration be seen. This might be due to the fact that the survival time after operation was comparatively short. However, even in experiments where we allowed a considerable survival time in order to see how long a Marchi positive stain could be obtained (Glees, 1943), no retrograde degeneration was to be seen.

We have already pointed out that axonal cutting was not enough to produce retrograde Marchi degeneration, but that de-afferentation seems also to be required. It should however be stressed that even if these two conditions are fulfilled a considerable time elapses before retrograde degeneration becomes apparent. This fact is borne out by the present cases. The survival time after tractotomy in the case of R.W. was 49 days and eight months in M.W. The retrograde fibre changes are more marked in M.W. Furthermore, in both cases they are more conspicuous towards the parent cells of the fibres involved. We assume that de-afferentation and axonal cutting will eventually cause cell death with retrograde Marchi degeneration of the central axonal stump, but that this process takes a considerable time, and we also gained the impression that the proximal segments are involved first. Should this be the case, the mode 
of this type of retrograde degeneration may be slightly different from that found in fibres of the pyramidal system (Glees, 1948), where the Wallerian degeneration, appearing already at the third day, affected every part of the fibre almost simultaneously from the lesion to the periphery, while the retrograde degeneration seems to progress distally from the cell body.

As was to be expected, the fibres showing retrograde Marchi degeneration originating from the left nucleus gracilis occupied a definite position in the brain stem. This finding is of help in localizing the position of the fibres of the nucleus gracilis in relation to those of the nucleus cuneatus (Figs. 5, 6). The fibres from the nucleus gracilis lie ventral and lateral to fibres of the nucleus cuneatus and occupy a similar position to that which Ferraro and Barrera (1936) pointed out for the monkey and Glees, Liddell, and Phillips (1951) found in the cat.

\section{Summary}

Two patients with a chronic lesion of the lower spinal cord had subsequently a right mid-brain tractotomy and survived for 49 days (R.W.) and eight months (M.W.) respectively. Retrograde fibre changes of that part of the medial fillet which originates from the left nucleus gracilis were seen, as well as death of the parent cells in the nucleus gracilis.

No retrograde changes were apparent in Marchi preparations in fillet fibres originating either in the left nucleus cuneatus or in the right nucleus gracilis or cuneatus.
While chromatolytic changes in the parent cells after axonal cutting will invariably occur, our material indicates that cell death combined with retrograde fibre changes of the central portion of the axon is certain only if there has been both de-afferentation and axonal cutting.

Our thanks are due to Miss A. G. Smith, Mr. T. A. Marsland, Mr. A. Austin, and Miss C. C. Boulter for their help.

\section{REFERENCES}

Brodal, A. (1939). Z. Zes. Neurol. Psychiat., 166, 646. Clark, W. E. Le Gros. (1932). Brit. J. Ophthal., 16, 264. Combs, C. M. (1951). J. comp. Neurol., 94, 123.

Ferraro, A., and Barrera, S. E. (1936). Ibid., 64, 313. Glees, P. (1943). Brain, 66, 229.

--(1946). J. Neuropath. exp. Neurol., 5, 54.

(1948). Acta anat., Basel, 6, 447.

, and Bailey, R. A. (1951). Mschr. Psychiat. Neurol., $122,129$.

12, Liddell, E. G. T., and Phillips, C. G. (1951). Z.Zellforsch.. 35, 487.

--, Livingston, R. B., and Soler, J. (1951). Arch. Psychiat. Neurol., 187, 190.

-_, and Soler, J. (1951). Z. Zellforsch., 36, 381.

, and Zander, E. (1950). Mschr. Psychiat. Neurol., 120, 21.

Minkowski, M. (1913). Arb. hirnanat. Ins . Zürich, 7, 255.

Penman, J., and Smith, M. C. (1950). Journal of Neurology, Neurosurgery and Psychiatry, 13, 36.

Raimann, E. (1900). Jb. Psychiat. Neurol., 19, 36.

Pilcz, A. (1899). Ibid., 18, 341.

Spatz, H. (1920). Z. ges. Neurol. Psychiat., 58, 327. (1921). Histol. histopath., Arb., Erg.-Bd., (ed. Nissl, F.) p. 49.

Spielmeyer, W. (1922). " Histopathologie des Nervensystems." Berlin.

Swank, R. L., and Davenport, H. A. (1935). Stain Tech., 10, 87. 